Article

\title{
One-Step Photocontrolled Polymerization-Induced Self-Assembly (Photo-PISA) by Using In Situ Bromine-Iodine Transformation Reversible-Deactivation Radical Polymerization
}

\author{
Haihui $\mathrm{Li}^{\dagger}{ }^{\dagger}$, Qinghua $\mathrm{Xu}^{\dagger}{ }^{+}$, Xiang $\mathrm{Xu}^{\dagger}{ }^{+}$, Lifen Zhang $* \mathbb{0}$, Zhenping Cheng ${ }^{*}$ and Xiulin Zhu \\ State and Local Joint Engineering Laboratory for Novel Functional Polymeric Materials, Jiangsu Key Laboratory of \\ Advanced Functional Polymer Design and Application, Suzhou Key Laboratory of Macromolecular Design and \\ Precision Synthesis, College of Chemistry, Chemical Engineering and Materials Science, Soochow University, \\ 199 Ren-ai Road, Suzhou 215123, China; harvey1119@163.com (H.L.); 15250060196@163.com (Q.X.); \\ xudongqi1818@163.com (X.X.); xlzhu@suda.edu.cn (X.Z.) \\ * Correspondence: zhanglifen@suda.edu.cn (L.Z.); chengzhenping@suda.edu.cn (Z.C.); \\ Fax: +86-512-65882787 (Z.C.) \\ + Haihui Li, Qinghua Xu and Xiang Xu contributed equally to this work.
}

Received: 10 December 2019; Accepted: 6 January 2020; Published: 7 January 2020

check for updates

\begin{abstract}
Polymerization-induced self-assembly (PISA) has become an effective strategy to synthesize high solid content polymeric nanoparticles with various morphologies in situ. In this work, one-step PISA was achieved by in situ photocontrolled bromine-iodine transformation reversible-deactivation radical polymerization (hereinafter referred to as Photo-BIT-RDRP). The water-soluble macroinitiator precursor $\alpha$-bromophenylacetate polyethylene glycol monomethyl ether ester (mPEG $1 \mathrm{k}-\mathrm{BPA})$ was synthesized in advance, and then the polymer nanomicelles (mPEG ${ }_{1 \mathrm{k}}-b$-PBnMA and mPEG $_{1 \mathrm{k}}-b$-PHPMA, where BnMA means benzyl methacrylate and HPMA is hydroxypropyl methacrylate) were successfully formed from a PISA process of hydrophobic monomer of BnMA or HPMA under irradiation with blue LED light at room temperature. In addition, the typical living features of the photocontrolled PISA process were confirmed by the linear increase of molecular weights of the resultant amphiphilic block copolymers with monomer conversions and narrow molecular weight distributions $\left(M_{\mathrm{W}} / M_{\mathrm{n}}<1.20\right)$. Importantly, the photocontrolled PISA process is realized by only one-step method by using in situ photo-BIT-RDRP, which avoids the use of transition metal catalysts in the traditional ATRP system, and simplifies the synthesis steps of nanomicelles. This strategy provides a promising pathway to solve the problem of active chain end (C-I) functionality loss in two-step polymerization of BIT-RDRP.
\end{abstract}

Keywords: photopolymerization; reversible-deactivation radical polymerization (RDRP); polymerizationinduced self-assembly (PISA); bromine-iodine transformation; photocontrolled

\section{Introduction}

In the past 20 years, the development of polymer synthesis technology has brought convenience to the preparation of polymers with different topologies, such as linear, grafted, branched, and ring-shaped. Intensive studies have shown that under certain conditions, existing polymers with different structures can self-assemble to form structured aggregates. Among these polymers, the linear block copolymer has the simplest structure, so the investigation of its self-assembly behaviour is the most extensive and in-depth [1,2]. The self-assembly of block copolymers has a wide range of applications in materials, chemistry, nanoscience, and biomedicine [3,4]. However, in the conventional method, in order to 
obtain a better nanostructure morphology, the concentration of the block copolymer solution needs to be highly diluted $[5,6]$, which limits its potential application. In recent years, polymerization-induced self-assembly (PISA) has attracted great attention [7]. In a PISA, the polymerization and the self-assembly processes are performed simultaneously, so the synthesis steps are greatly simplified compared to the conventional self-assembly method [8,9]. In addition, PISA has many advantages over traditional methods, such as rich assembly morphologies [7], high solid content [10], and suitability for various solvents [11,12], and the morphologies of the nanostructures can be controlled by adjusting the molar ratio of hydrophilic and hydrophobic segments during PISA process [13]. PISA is theoretically suitable for all reversible-deactivation radical polymerization (RDRP) such as atom transfer radical polymerization (ATRP), reversible addition-fragmentation chain transfer (RAFT) polymerization and iodine transfer radical polymerization (ITP) [7,14-17]. However, the more in-depth study of PISA is currently carried out by RAFT polymerization due to the absence of transition metal during PISA process [7,18-21].

Alkyl iodides (R-I) are usually used as initiators and regulators in iodine-mediated RDRP [22-25]. However, the bond dissociation energy of the C-I bond is relatively low, so alkyl iodides are usually unstable and need special storage conditions, which limits the practical application of this polymerization method [26]. Recently, Goto's group [26] and our group [27] reported thermal-initiated and photocontrolled in situ bromine-iodine transformation RDRP (BIT-RDRP) strategies, respectively. This method generates R-I in situ in a polymerization system by a nucleophilic substitution reaction of a relatively stable atom transfer radical polymerization (ATRP) initiator alkyl bromide (R-Br) with $\mathrm{NaI}$ (Scheme 1). Since commercially available ATRP R-Br initiators are used as the precursors in a BIT-RDRP process, this strategy avoids the introduction of transition metal catalysts usually used in a transition metal-mediated ATRP system. On the other hand, a PISA usually requires a two-step procedure. Generally, the solvent-soluble block is obtained in the first step, and then it is used as a macroinitiator to initiate the polymerization of the nucleating monomer to form an amphiphilic block copolymer in situ [28]. Very recently, our group introduced the first photo-BIT-RDRP into a two-step PISA process, and different micelle morphologies (spherical micelles and vesicle aggregates) were controllably generated by the two-step photo-BIT-RDRP-PISA method using polyethylene glycol methacrylate (PEGMA) and benzyl methacrylate (BnMA) as hydrophilic and hydrophobic monomer, respectively [29]. Through this strategy, we have successfully established a new PISA method by combination the advantages of both ATRP and iodine-mediated RDRP, which avoiding the use of transition metals in the ATRP and overcoming the shortcomings of the unstability of alkyl iodide initiator in the iodine-mediated RDRP method [29].

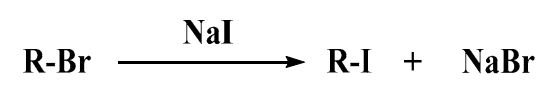

Scheme 1. In situ nucleophilic substitution reaction.

It is well-known that the functional chain end of the polymer-I (C-I bond) is relatively active and easy to cause an unavoidable functionality loss during the process of conventional polymerization post-treatment. Therefore, there is a drawback of functionality loss of the macroinitiator polymer-I obtained in the first step for the two-step photo-BIT-RDRP-PISA mentioned above. Therefore, it is highly desired to construct a one-step in situ bromine-iodine transformation RDRP-PISA (BIT-RDRP-PISA) system, especially photo-BIT-RDRP-PISA system, which will simplify the polymerization procedure and reduce the loss of active C-I chain ends significantly. Based on this purpose, in this work, we first focused on the synthesis of a water-soluble alkyl bromide as a macroinitiator precursor $\left(\mathrm{mPEG}_{1 \mathrm{k}}\right.$-BPA) instead of R-Br in the two-step photo-BIT-RDRP-PISA. Subsequently, the one-step photo-BIT-RDRP-PISA process (Scheme 2) was smoothly carried out by using mPEG $_{1 \mathrm{k}}$-IPA, a product of in situ bromine-iodine transformation nucleophilic substitution of PPEG $_{1 k}$-BPA with $\mathrm{NaI}[27,29]$, as the alkyl iodide macroinitiator to initiate a PISA process in methanol in the presence of the hydrophobic 
monomer (BnMA or hydroxypropyl methacrylate (HPMA)) under irradiation with blue LED light at room temperature.

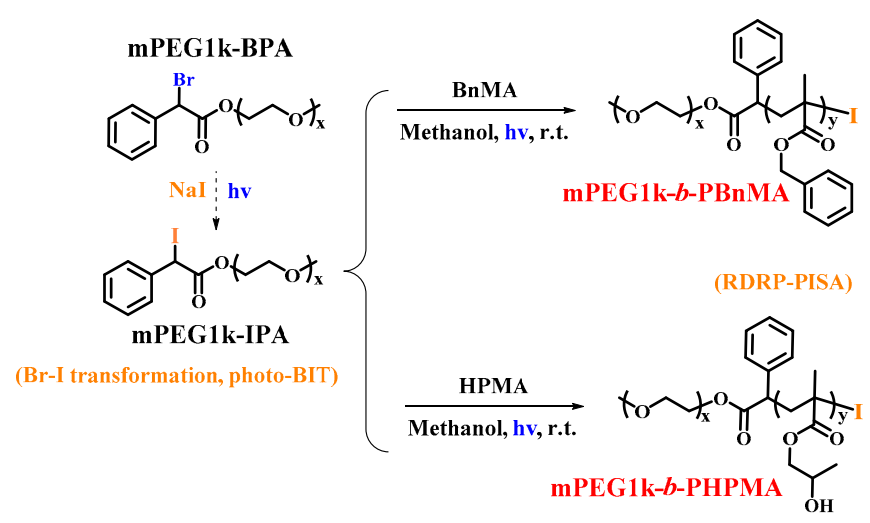

Scheme 2. Synthetic routes of $\mathrm{mPEG}_{1 \mathrm{k}}-b$-PBnMA and $\mathrm{mPEG}_{1 \mathrm{k}}-b$-PHPMA nanoparticles by using one-step photo-BIT-RDRP-PISA strategy.

\section{Experimental}

\subsection{Materials}

Benzyl methacrylate (BnMA, 98\%, J\&K, Shanghai, China) and hydroxypropyl methacrylate (HPMA, 99\%, Energy Chemical, Shanghai, China) were passed through an alumina column to remove the inhibitor. Polyethylene glycol monomethyl ether ( $\left.\mathrm{mPEG}_{1 \mathrm{k}}, M_{\mathrm{n}}=1000 \mathrm{~g} / \mathrm{mol}, 97 \%\right)$ was purchased from TCI (Shanghai, China). 2-Bromo-2-phenylacetic acid (98\%), sodium iodide (97\%) and triethylamine (99.5\%) were also purchased from TCI (Shanghai, China). Dichlorosulfane (98\%), anhydrous methanol (99.5\%), anhydrous ether, tetrahydrofuran (99.5\%) and all other chemicals were obtained from Shanghai Chemical Reagents Co. Ltd. (Shanghai, China) and used as received unless otherwise mentioned.

\subsection{Characterization}

The number average molecular weight $\left(M_{n, G P C}\right)$ and molecular weight distribution $\left(M_{\mathrm{w}} / M_{\mathrm{n}}\right)$ values of the resulting polymers were determined using a HLC-8320 gel permeation chromatograph (GPC, TOSOH, Kyoto, Japan) equipped with a refractive-index detector (TOSOH), using a TSKgel guard column SuperMP-N $(4.6 \times 20 \mathrm{~mm})$ and two TSKgel SupermultiporeHZ-N $(4.6 \times 150 \mathrm{~mm})$, with measurable molecular weights ranging from $5 \times 10^{2}$ to $5 \times 10^{5} \mathrm{~g} / \mathrm{mol}$. THF was used as an eluent at a flow rate of $0.35 \mathrm{~mL} / \mathrm{min}$ operated at $40{ }^{\circ} \mathrm{C}$. GPC samples were injected using a TOSOH plus autosampler and calibrated with polymethyl methacrylate (PMMA) standards purchased from TOSOH. ${ }^{1} \mathrm{H}$ NMR spectra of the polymers were recorded on a Bruker (Beijing, China) $300 \mathrm{MHz}$ nuclear magnetic resonance (NMR) instrument using $\mathrm{CDCl}_{3}$ or DMSO- $d_{6}$ as the solvent and tetramethylsilane (TMS) as an internal standard at ambient temperature. The UV-visible absorption spectrum was measured by a UV-2600 UV-Vis spectrophotometer (Shimadzu, Kyoto, Japan) with methanol as the solvent. The morphology of the polymeric nanoparticles was obtained by a TecnaiG22 transmission electron microscope (TEM, FEI, Hillsboro, OH, USA) with an accelerating voltage of $120 \mathrm{kV}$. Take $4 \mu \mathrm{L}$ of the polymer mixture solution in a dry and clean ampule, dilute with $5 \mathrm{~mL}$ of methanol solvent, and then pipet $10 \mu \mathrm{L}$ of the solution $(0.5 \mathrm{mg} / \mathrm{mL})$ onto a 200 mesh carbon-coated copper mesh. After standing for $40 \mathrm{~s}$, filter paper was used to remove excess solvent from under the copper mesh. In order to facilitate the observation of the morphology of the polymer nanoparticles, it is necessary to dye the aqueous solution with a concentration of $1.0 \% w / w$ of phosphotungstic acid. Therefore, $10 \mu \mathrm{L}$ of an aqueous solution of phosphotungstic acid was pipetted onto a copper mesh to which polymeric nanoparticles had been dropped. After standing for $20 \mathrm{~s}$, filter paper was used to remove excess solvent from under 
the copper mesh. Dynamic light scattering (DLS) measurements were conducted using a NanoBrook 90 Plus instrument (BIC, Huntsville, NY, USA). The intensity weighted mean hydrodynamic diameter and the particle size distribution were obtained from the analysis of the autocorrelation functions using the cumulants method. At least three measurements at $25^{\circ} \mathrm{C}$ were made for each sample $(0.10 \% w / w$ dispersions) with an equilibrium time of $2 \mathrm{~min}$ before starting the measurement.

\subsection{Synthesis and Characterization of $m P E G_{1 k}-B P A$}

The polyethylene glycol monomethyl ether 2-bromo-2-phenylacetate ( $\mathrm{mPEG}_{1 \mathrm{k}}$-BPA) was synthesized according to the method in the reference [30]. The typical procedure is shown in Scheme 3. Firstly, $20 \mathrm{~mL}$ of dichlorosulfane and $8.6 \mathrm{~g}$ of 2-bromo-2-phenylacetic acid $(40 \mathrm{mmol})$ were added to a $50 \mathrm{~mL}$ three-necked flask. The temperature was raised to $70{ }^{\circ} \mathrm{C}$ under magnetic stirring and refluxed for $6 \mathrm{~h}$. After cooling to room temperature, the remaining dichlorosulfane was removed by rotary evaporation to obtain 2-bromo-2-phenylacetyl chloride (1). Its structure was clearly characterized by NMR spectroscopy $\left({ }^{1} \mathrm{H}-\mathrm{NMR}\left(300 \mathrm{MHz}, \mathrm{CDCl}_{3}, \mathrm{TMS}, \delta, \mathrm{ppm}\right): 7.59-7.32(\mathrm{~m}, 5 \mathrm{H})\right.$, $5.94(\mathrm{~s}, 1 \mathrm{H})$.

Then, in a $250 \mathrm{~mL}$ three-necked flask, $8.1 \mathrm{~g}$ of $\mathrm{mPEG}_{1 \mathrm{k}}, 0.5 \mathrm{~mL}$ of triethylamine and $150 \mathrm{~mL}$ of anhydrous dichloromethane were added. $5 \mathrm{~g}$ of (1) was added dropwise with a constant pressure dropping funnel under ice bath $\left(0{ }^{\circ} \mathrm{C}\right)$. After the addition was completed, increasing temperature to $30^{\circ} \mathrm{C}$ for $36 \mathrm{~h}$. The dichloromethane was removed by rotary evaporation. The product was dissolved with a small amount of tetrahydrofuran (THF) and then precipitated in anhydrous ether. This process was repeated three times. Then a white solid ( $\left.\mathrm{mPEG}_{1 \mathrm{k}}-\mathrm{BPA}\right)$ was collected by suction filtration. Its structure was verified by NMR spectroscopy $\left({ }^{1} \mathrm{H}-\mathrm{NMR}, 300 \mathrm{MHz}, \mathrm{CDCl}_{3}, \mathrm{TMS}, \delta, \mathrm{ppm}\right)$ : 7.60-7.31 (m, 5H), $5.39(\mathrm{~s}, 1 \mathrm{H}), 4.34(\mathrm{~d}, 2 \mathrm{H}), 3.98-3.51(\mathrm{~m}, 90 \mathrm{H}), 3.38(\mathrm{~s}, 3 \mathrm{H}), 2.10(\mathrm{~s}, 2 \mathrm{H})$.

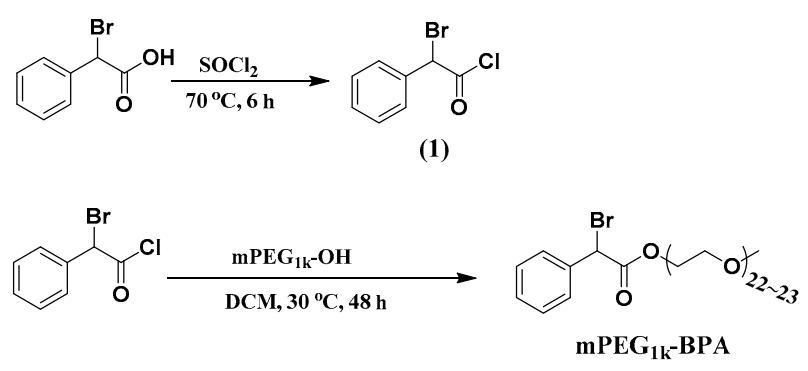

Scheme 3. The synthetic route of $\mathrm{mPEG}_{1 \mathrm{k}}-\mathrm{BPA}$.

\subsection{General Procedure for the Polymerization of BnMA or HPMA}

We conducted the polymerization in ampules under an argon (Ar) atmosphere, and the light source is blue light-emitting diode (LED) light strip $\left(\lambda_{\max }=464 \mathrm{~nm}, 0.15 \mathrm{~mW} / \mathrm{cm}^{2}\right)$. A typical polymerization procedure for the molar ratio of $[\mathrm{BnMA}]_{0} /\left[\mathrm{mPEG}_{1 \mathrm{k}}-\mathrm{BPA}\right]_{0} /[\mathrm{NaI}]_{0} /[\mathrm{TEA}]_{0}=20 / 1 / 2 / 0.5$ is shown as follows: a mixture of $\mathrm{mPEG}_{1 \mathrm{k}}-\mathrm{BPA}(14.8 \mathrm{mg}, 0.015 \mathrm{mmol}), \mathrm{NaI}(4.4 \mathrm{mg}, 0.03 \mathrm{mmol}), \mathrm{BnMA}$ $(50 \mu \mathrm{L}, 0.30 \mathrm{mmol})$, TEA $(1.0 \mu \mathrm{L}, 0.0075 \mathrm{mmol})$, and methanol $(0.50 \mathrm{~mL})$ was added to a dried ampule $(2 \mathrm{~mL})$ with a stir bar. The mixed solution was a pale yellow homogeneous solution. After three freeze-pump-thaw cycles to eliminate the dissolved oxygen and provide an Ar atmosphere, the ampule was flame-sealed. The mixture was transferred to a stirring device equipped with a blue LED strip, cooling with an electric fan to remove heat from the LED strip. The polymerization was maintained at room temperature $\left(25^{\circ} \mathrm{C}\right)$. After a desired polymerization time, the ampule was moved to a dark place, and $20 \mu \mathrm{L}$ of the polymer solution was pipetted into a solvent of DMSO- $d_{6}$ and subjected to ${ }^{1} \mathrm{H}-\mathrm{NMR}$ characterization for monomer conversion. For the polymerization of HPMA, a mixture of polymerization solution was obtained with the molar ratio of $[\mathrm{HPMA}]_{0} /\left[\mathrm{mPEG}_{1 \mathrm{k}}-\mathrm{BPA}\right]_{0} /[\mathrm{NaI}]_{0} /[\mathrm{TEA}]_{0}$ = 300/1/2/1 (PEG1k-BPA: 14.8 mg, 0.015 mmol; NaI: 4.4 mg, 0.03 mmol; HPMA: 0.5 mL, 3.5 mmol; TEA: 
$1.72 \mu \mathrm{L}, 0.012 \mathrm{mmol}$ ) in a mixed solvent of $1.67 \mathrm{~mL}$ of methanol and $0.83 \mathrm{~mL}$ of water, and the rest procedure was the same as that for the polymerization of BnMA mentioned above.

\section{Results and Discussion}

\subsection{Polymerization Mechanism}

Firstly, blue light plays a vital role in the photo-BIT-RDRP system. Our previous research demonstrated that the type of light source has a significant effect on the monomer conversion, molecular weight, and molecular weight distribution of the resultant polymers [27]. Compared with light sources of other wavelengths, the blue light we selected has relatively good control over the polymerization process. On the other hand, the occurrence and stop of the polymerization reaction strictly follow the light on and off, which makes the polymerization method have excellent spatiotemporal controllability $[27,29]$.

As reported by our previous work, the photo-BIT-RDRP process will result in the formation of a small amount of iodine [27]. Therefore, the UV-vis absorption spectra were used to verify whether $\mathrm{I}_{2}$ was generated during the polymerization. We measured the UV-visible absorption spectra of TEA, $\mathrm{mPEG}_{1 \mathrm{k}}-\mathrm{BPA}$ and the reaction solution after $7 \mathrm{~h}$ of polymerization $\left([\mathrm{BnMA}]_{0} /\left[\mathrm{mPEG}_{1 \mathrm{k}}-\mathrm{BPA}\right]_{0} /[\mathrm{NaI}]_{0} /\right.$ $[T E A]_{0}=20 / 1 / 2 / 0.5$ ) (Figure 1). TEA and $\mathrm{mPEG}_{1 \mathrm{k}}-\mathrm{BPA}$ have absorption in the wavelength range of 200-300 nm, and no absorption in the wavelength range of more than $300 \mathrm{~nm}$. However, after $7 \mathrm{~h}$ of polymerization, absorption peaks appeared at $365 \mathrm{~nm}$ and $297 \mathrm{~nm}$. In comparison to the UV-vis absorption spectra of the $\mathrm{I}_{2}$ and $\mathrm{I}_{2}$-TEA complexes, there actually exists the absorption peak of the resulting $\mathrm{I}_{2}$-TEA complex. This proves that there is indeed a small amount of $\mathrm{I}_{2}$ formation during the polymerization. On the other hand, the polymerization solution was pale yellow before irradiation with blue LED light. However, after irradiation, the color of polymerization solution gradually became darker, which proved the formation of a small amount of iodine again. Therefore, we can propose the polymerization mechanism of this one-step photo-BIT-RDRP, which is similar with that of typical reversible complexation mediated polymerization (RCMP) as reported previously [31-34], and is shown in Scheme 4. The ATRP macroinitiator mPEG1k-BPA (PEG-Br) was first transferred into PPEG $_{1 \mathrm{k}}$-IPA (PEG-I) in the presence of NaI under irradiation with blue LED light. The in situ generated PEG-I was used as the starting RCMP macroinitiator to initiate the monomer polymerization and therefore to form the propagating polymer chains $\mathrm{P}_{\mathrm{n}}-\mathrm{I}$. It should be noted that the halogen bond interaction can be formed between TEA and iodine in the presence of catalyst TEA $[17,35]$. Thereby the C-I bond can be cleaved easily under irradiation with blue LED light to generate the carbon-centered propagating radicals $\left(\mathrm{P}_{\mathrm{n}} \bullet\right)$ and iodine radical $/ \mathrm{H}_{2} \mathrm{O}$ complex $\left(\mathrm{I}_{\bullet} / \mathrm{H}_{2} \mathrm{O}\right.$ complex $)$. At the same time $\mathrm{P}_{\mathrm{n}} \bullet$ can reversibly combine the iodine radical to form a dormant species $\mathrm{P}_{\mathrm{n}}-\mathrm{I}$, and a small amount of the free iodine radicals can also combine to form $\mathrm{I}_{2}$ during the polymerization process as observed in Figure 1 .

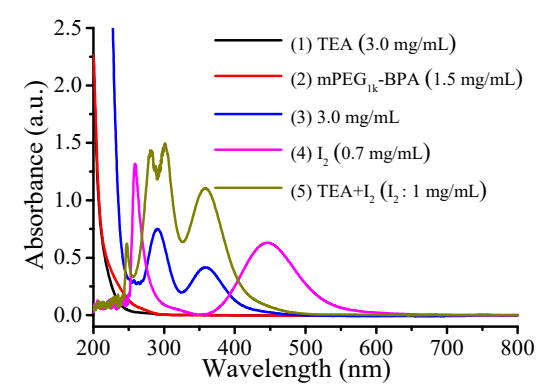

Figure 1. UV-vis absorption spectra of the (1) TEA, (2) $\mathrm{mPEG}_{1 \mathrm{k}}-\mathrm{BPA}$, (3) polymerization conditions: $[\mathrm{BnMA}]_{0} /\left[\mathrm{mPEG}_{1 \mathrm{k}}-\mathrm{BPA}\right]_{0} /[\mathrm{NaI}]_{0} /[\mathrm{TEA}]_{0}=20 / 1 / 2 / 0.5, V_{\mathrm{BnMA}}=50 \mu \mathrm{L}$, under irradiation with blue LED light $\left(\lambda_{\max }=464 \mathrm{~nm}, 0.15 \mathrm{~mW} \mathrm{~cm}^{-2}\right)$ at room temperature $\left(25^{\circ} \mathrm{C}\right)$ after $7 \mathrm{~h},(4) \mathrm{I}_{2},(5) \mathrm{TEA} / \mathrm{I}_{2}=4: 1$. The samples were diluted with methanol before measurement. 


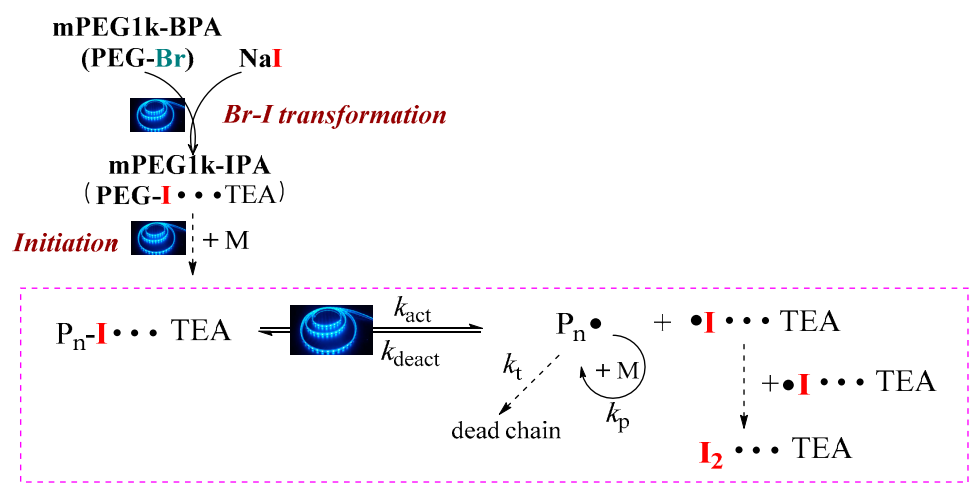

Scheme 4. Proposed polymerization mechanism by using one-step photo-BIT-RDRP strategy.

\subsection{In Situ Photo-BIT-RDRP of BnMA and Its Self-Assembly Behavior}

We investigated the polymerization behaviors of BnMA using $\mathrm{mPEG}_{1 \mathrm{k}}-\mathrm{BPA}$ as the macroinitiator under irradiation with blue LED light at room temperature. As can be seen from Figure $2 \mathrm{a}, \ln \left([\mathrm{M}]_{0} /[\mathrm{M}]\right)$ grows very slowly over time in 0 to $5 \mathrm{~h}$, indicating that the increase in the polymerization degree of PBnMA before $5 \mathrm{~h}$ is not enough to achieve micelle nucleation. However, after $5 \mathrm{~h}, \ln \left([\mathrm{M}]_{0} /[\mathrm{M}]\right)$ increases linearly with polymerization time. It is due to the increase in viscosity after micelle nucleation, and the monomer is encapsulated inside $\mathrm{mPEG}_{1 \mathrm{k}}-b$-PBnMA, resulting in an increase in local monomer concentration. Therefore, the polymerization rate is significantly accelerated. From Figure $2 b$, the molecular weights of the resultant amphiphilic block copolymers increase linearly with monomer conversion, and the molecular weight distributions keep narrow $\left(M_{\mathrm{W}} / M_{\mathrm{n}}<1.20\right)$. It is noted that there are some deviations in molecular weights measured by GPC $\left(M_{n, \mathrm{GPC}}\right)$ from the theoretical ones $\left(M_{n, t h}\right)$ since PMMA was used as the standard for calibration in GPC; however, the molecular weights determined by NMR spectra $\left(M_{n, N M R}\right)$ was close to their corresponding $M_{n, t h}$ values. In addition, as shown in Figure 2c, there is an obvious peak shift after block polymerization with BnMA. These facts indicate that the photo-BIT-RDRP of BnMA is consistent with the typical feature of RDRP. The self-assembly morphology of the $\mathrm{mPEG}_{1 \mathrm{k}}-b-\mathrm{PBnMA}_{\mathrm{x}}(\mathrm{x}=3,8$, and 15) at different degrees of polymerization is shown in Figure 3 (the detailed information is shown in Table 1). Figure $3 \mathrm{~A}$ is a topographical view of the block PBnMA with the degree of polymerization (DP) of 3. At this time, the insoluble segments are shorter, so that the particle size of the micelles formed is small (about $12.8 \mathrm{~nm}$ ). In Figure 3B, for DP 8, the particle size increases to $43.2 \mathrm{~nm}$. As shown in Figure 3C, the particle size of the assembled spherical polymer micelles increased to $177.1 \mathrm{~nm}$ correspondingly.
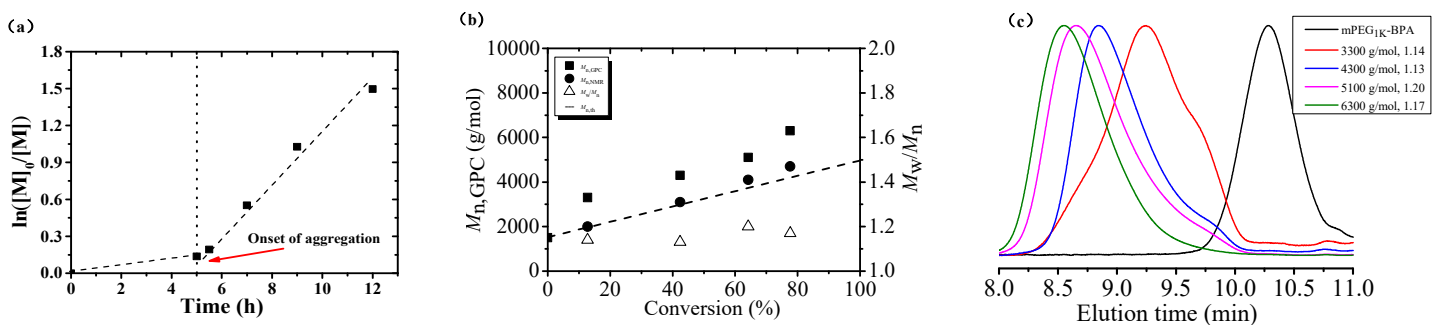

Figure 2. $\ln \left([\mathrm{M}]_{0} /[\mathrm{M}]\right)$ as a function of time (a), number-average molecular weight $\left(M_{\mathrm{n}, \mathrm{GPC}}\right)$ and molecular weight distribution $\left(M_{\mathrm{W}} / M_{\mathrm{n}}\right)$ versus monomer conversion (b) and GPC elution curves (c) for photo-BIT-RDRPof BnMA. Polymerization conditions: $[\mathrm{BnMA}]_{0} /\left[\mathrm{mPEG}_{1 \mathrm{k}}-\mathrm{BPA}\right]_{0} /[\mathrm{NaI}]_{0} /[\mathrm{TEA}]_{0}$ $=20 / 1 / 2 / 0.5, V_{\mathrm{BnMA}}=50 \mu \mathrm{L}, V_{\text {methanol }}=0.5 \mathrm{~mL}$, under irradiation with blue LED light $\left(\lambda_{\max }=464 \mathrm{~nm}\right.$, $\left.0.15 \mathrm{~mW} / \mathrm{cm}^{2}\right)$ at room temperature $\left(25^{\circ} \mathrm{C}\right)$; BnMA concentration at $20.0 \mathrm{wt} \%$. 


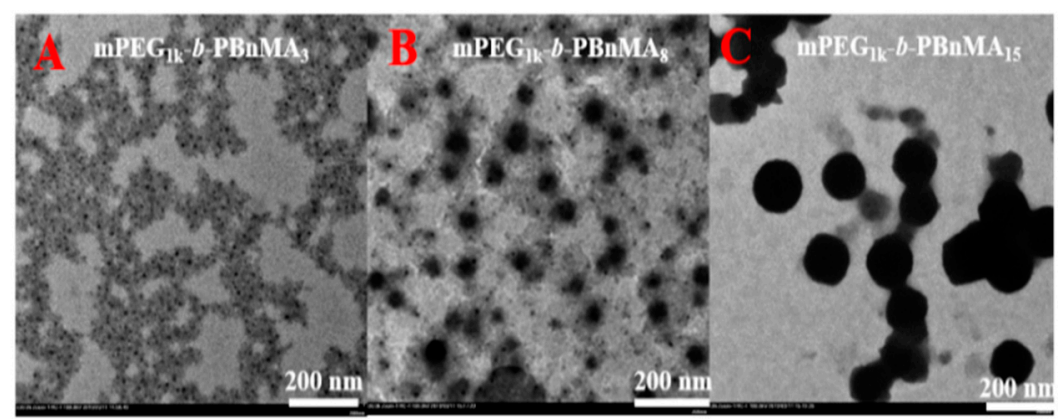

Figure 3. TEM images $(\mathrm{A}-\mathrm{C})$ of micelles from $\mathrm{mPEG}_{1 \mathrm{k}}-b$-PBnMA$(\mathrm{x}=3,8$, and 15 , respectively) via one-step photo-BIT-RDRP-PISA using BnMA as the monomer. The samples obtained by the BnMA concentration at $20.0 \mathrm{wt} \%$.

Table 1. Polymerization of BnMA via photo-BIT-RDRP.

\begin{tabular}{|c|c|c|c|c|c|c|c|c|}
\hline Entry & Time(h) & Conv. $^{a}(\%)$ & $M_{\mathrm{n}, \mathrm{th}}{ }^{b}(\mathrm{~g} / \mathrm{mol})$ & $M_{\mathrm{n}, \mathrm{NMR}}{ }^{c}(\mathrm{~g} / \mathrm{mol})$ & $M_{\mathrm{n}, \mathrm{GPC}}(\mathrm{g} / \mathrm{mol})$ & $M_{\mathrm{w}} / M_{\mathrm{n}}$ & $\mathrm{DP}^{d}$ & Particle Size $(\mathrm{nm})^{e}$ \\
\hline A & 5.5 & 12.8 & 2000 & 2000 & 3300 & 1.14 & 3 & $12.8 \pm 2.4$ \\
\hline B & 7 & 42.4 & 3000 & 3100 & 4300 & 1.13 & 8 & $43.2 \pm 2.0$ \\
\hline $\mathrm{C}$ & 12 & 77.6 & 4200 & 4700 & 6300 & 1.17 & 15 & $177.1 \pm 2.7$ \\
\hline
\end{tabular}

Polymerization conditions: $[\mathrm{BnMA}]_{0} /\left[\mathrm{mPEG}_{1 \mathrm{k}}-\mathrm{BPA}\right]_{0} /[\mathrm{NaI}]_{0} /[\mathrm{TEA}]_{0}=20 / 1 / 2 / 0.5, V_{\mathrm{BnMA}}=50 \mu \mathrm{L}, V_{\text {methanol }}=0.5 \mathrm{~mL}$, under irradiation with blue LED light $\left(\lambda_{\max }=464 \mathrm{~nm}, 0.15 \mathrm{~mW} \mathrm{~cm}^{-2}\right)$ at room temperature $\left(25^{\circ} \mathrm{C}\right) .{ }^{a}$ Monomer conversion was calculated from ${ }^{1} \mathrm{H}$ NMR spectra results. ${ }^{b} M_{\mathrm{n}, \mathrm{h}}=\left[\mathrm{BnMA}_{0} /\left[\mathrm{mPEG}_{1 \mathrm{k}}-\mathrm{BPA}\right]_{0} \times M_{\mathrm{BnMA}} \times\right.$ Conv. $\%+$ $M_{\mathrm{n}, \mathrm{mPEG} 1 \mathrm{k}-\mathrm{BPA} .}{ }^{c}$ Molecular weight calculated from ${ }^{1} \mathrm{H}$ NMR spectra results. ${ }^{d}$ Degree of polymerization calculated from Conv. $\% .{ }^{e}$ Obtained from TEM images.

\subsection{In Situ Photo-BIT-RDRP of HPMA and Its Self-Assembly Behavior}

HPMA has considerable solubility in methanol or water, while PHPMA has poor solubility, especially for high molecular weight PHPMA in water. Therefore, HPMA is also an ideal monomer for a PISA process. We chose a mixed solution of methanol and water as the solvent. Figure 4 is a topographical view of the assembly of $\mathrm{mPEG}_{1 \mathrm{k}}-b-\mathrm{PHPMA}_{\mathrm{x}}(\mathrm{x}=75,105,181)$ with different degrees of polymerization observed by TEM (polymerization information is shown in Table 2). When the DP is 75, the particle size of the self-assembled nanoparticles is about $34.2 \mathrm{~nm}$. Increasing DP to 105, the particle size of the nanoparticles increased to $50.1 \mathrm{~nm}$. Further increasing the DP to 181, the nanoparticles correspondingly increased to $102.9 \mathrm{~nm}$. Therefore, the size of the resultant nanoparticles can be easily controlled by adjusting the degree of polymerization during the photo-BIT-RDRP-PISA process.
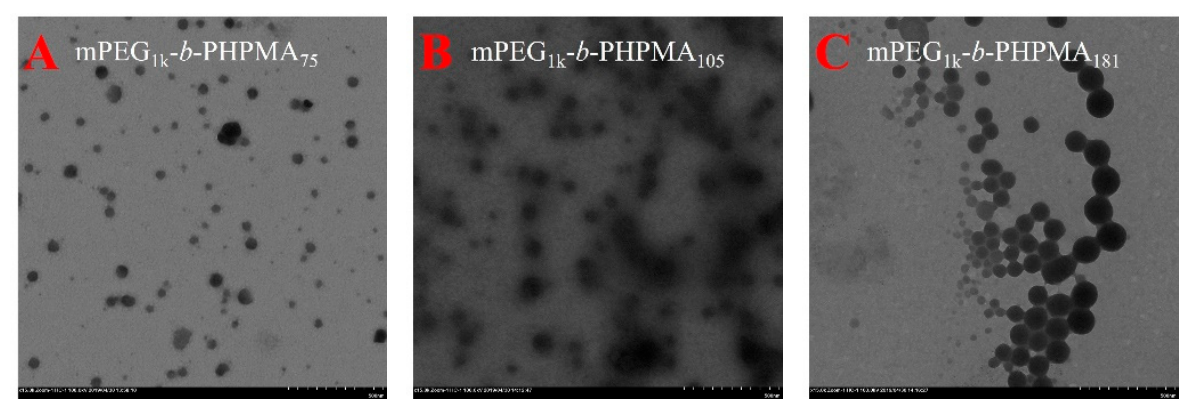

Figure 4. TEM images (A-C) of micelles from mPEG $_{1 \mathrm{k}}-b$-PHPMA $\mathrm{x}(\mathrm{x}=75,105$, and 181, respectively) via one-step photo-BIT-RDRP-PISA using HPMA as the monomer. The samples obtained by the HPMA concentration at $20.0 \mathrm{wt} \%$. 
Table 2. Polymerization of HPMA via photo-BIT-RDRP.

\begin{tabular}{cccccccc}
\hline Entry & $\begin{array}{c}\text { Time } \\
(\mathbf{h})\end{array}$ & $\begin{array}{c}\text { Conv. } \\
\mathbf{( \% )}\end{array}$ & $\begin{array}{c}\boldsymbol{M}_{\mathbf{n}, \mathbf{t h}} \boldsymbol{b} \\
(\mathbf{g} / \mathbf{m o l})\end{array}$ & $\begin{array}{c}\boldsymbol{M}_{\mathbf{n}, \mathrm{GPC}} \\
\mathbf{( g / m o l )}\end{array}$ & $\boldsymbol{M}_{\mathbf{w}} / \boldsymbol{M}_{\mathbf{n}}$ & $\mathbf{D P}^{\boldsymbol{c}}$ & Particle Size (Đ) $^{\boldsymbol{d}}$ \\
\hline $\mathrm{A}$ & 6 & 25 & 12,300 & 17,200 & 1.34 & 75 & $34.2(0.208)$ \\
$\mathrm{B}$ & 8 & 35.1 & 16,700 & 22,300 & 1.28 & 105 & $50.1(0.163)$ \\
$\mathrm{C}$ & 12 & 60.4 & 27,600 & 33,500 & 1.28 & 181 & $102.9(0.260)$ \\
\hline
\end{tabular}

Polymerization conditions: $[\mathrm{HPMA}]_{0} /\left[\mathrm{mPEG}_{1 \mathrm{k}}-\mathrm{BPA}\right]_{0} /[\mathrm{NaI}]_{0} /[\mathrm{TEA}]_{0}=300 / 1 / 2 / 1, V_{\mathrm{HPMA}}=0.5 \mathrm{~mL}, V_{\text {methanol }}=1.67 \mathrm{~mL}$,

$V_{\text {water }}=0.83 \mathrm{~mL}$, under irradiation with blue LED light $\left(\lambda_{\max }=464 \mathrm{~nm}, 0.15 \mathrm{~mW} \mathrm{~cm}{ }^{-2}\right)$ at room temperature $\left(25^{\circ} \mathrm{C}\right)$.

${ }^{a}$ Monomer conversion was calculated from ${ }^{1} \mathrm{H}$ NMR spectra results. ${ }^{b} M_{\mathrm{n}, \mathrm{th}}=[\mathrm{HPMA}]_{0} /\left[\mathrm{mPEG}_{1 \mathrm{k}}-\mathrm{BPA}\right]_{0} \times M_{\mathrm{HPMA}}$

$\times$ Conv. $\%+M_{n, \text { mPEG1k-BPA } .}{ }^{c}$ Degree of polymerization calculated from Conv. $\% .{ }^{d}$ Obtained by DLS.

\section{Conclusions}

In summary, we have synthesized a water-soluble macroinitiator $\mathrm{mPEG}_{1 \mathrm{k}}$-BPA and realized a one-step in situ photo-BIT-RDRP-PISA process under irradiation with blue LED light at room temperature, successfully obtaining $\mathrm{mPEG}_{1 \mathrm{k}}-b$-PBnMA and $\mathrm{mPEG}_{1 \mathrm{k}}-b$-PHPMA amphiphilic block copolymer micelles in situ. This strategy effectively improves the problem of the active chain end (C-I) loss caused by two-step bromine-iodine transformation RDRP-PISA process, and also greatly simplifies the synthesis step, which provides a promising method for the synthesis of polymeric nanoparticles by photo-BIT-RDRP-PISA strategy.

Author Contributions: Conceptualization, L.Z., Z.C. and X.Z.; Investigation, H.L., Q.X. and X.X.; Writing, H.L.; Supervision, L.Z. and Z.C. All authors have read and agreed to the published version of the manuscript.

Acknowledgments: Financial support from the National Natural Science Foundation of China (Nos. 21774082 and 21871201, and 21925107), the Nature Science Key Basic Research of Jiangsu Province for Higher Education (No. 16KJA150003), and the Project Funded by the Priority Academic Program Development of Jiangsu Higher Education Institutions (PAPD) is gratefully acknowledged.

Conflicts of Interest: The authors declare no conflict of interest.

\section{References}

1. Riess, G. Micellization of block copolymers. Prog. Polym. Sci. 2003, 28, 1107-1170. [CrossRef]

2. Mai, Y.; Eisenberg, A. Self-assembly of block copolymers. Chem. Soc. Rev. 2012, 41, 5969-5985. [CrossRef] [PubMed]

3. Tseng, Y.C.; Darling, S.B. Block Copolymer Nanostructures for Technology. Polymers 2010, 2, 470-489. [CrossRef]

4. Venkatesan, S.; Liu, I.P.; Li, C.W.; Tseng-Shan, C.M.; Lee, Y.L. Quasi-Solid-State Dye-Sensitized Solar Cells for Efficient and Stable Power Generation under Room Light Conditions. ACS Sustain. Chem. Eng. 2019, 7, 7403-7411. [CrossRef]

5. Bagheri, A.; Boyer, C.; Lim, M. Synthesis of Light-Responsive Pyrene-Based Polymer Nanoparticles via Polymerization-Induced Self-Assembly. Macromol. Rapid Commun. 2019, 40, 1800510. [CrossRef] [PubMed]

6. Darling, S.B. Directing the self-assembly of block copolymers. Prog. Polym. Sci. 2007, 32, 1152-1204. [CrossRef]

7. Derry, M.J.; Fielding, L.A.; Armes, S.P. Polymerization-induced self-assembly of block copolymer nanoparticles via RAFT non-aqueous dispersion polymerization. Prog. Polym. Sci. 2016, 52, 1-18. [CrossRef]

8. Tan, J.B.; Liu, D.D.; Bai, Y.H.; Huang, C.D.; Li, X.L.; He, J.; Xu, Q.; Zhang, X.C.; Zhang, L. An insight into aqueous photoinitiated polymerization-induced self-assembly (photo-PISA) for the preparation of diblock copolymer nano-objects. Polym. Chem. 2017, 8, 1315-1327. [CrossRef]

9. Mellot, G.; Guigner, J.M.; Bouteiller, L.; Stoffelbach, F.; Rieger, J. Templated PISA: Driving Polymerization-Induced Self-Assembly towards Fibre Morphology. Angew. Chem. Int. Ed. 2019, 58, 3173-3177. [CrossRef]

10. Wu, J.J.; Tian, C.; Zhang, L.F.; Cheng, Z.P.; Zhu, X.L. Synthesis of soap-free emulsion with high solid content by differential dripping RAFT polymerization-induced self-assembly. RSC Adv. 2017, 7, 6559-6564. [CrossRef]

11. Gao, C.Q.; Wu, J.P.; Zhou, H.; Qu, Y.Q.; Li, B.H.; Zhang, W.Q. Self-Assembled Blends of AB/BAB Block Copolymers Prepared through Dispersion RAFT Polymerization. Macromolecules 2016, 49, 4490-4500. [CrossRef] 
12. Jennings, J.; Beija, M.; Richez, A.P.; Cooper, S.D.; Mignot, P.E.; Thurecht, K.J.; Jack, K.S.; Howdle, S.M. One-Pot Synthesis of Block Copolymers in Supercritical Carbon Dioxide: A Simple Versatile Route to Nanostructured Microparticles. J. Am. Chem. Soc. 2012, 134, 4772-4781. [CrossRef] [PubMed]

13. Zhang, Y.M.; Filipczak, P.; He, G.P.; Nowaczyk, G.; Witczak, L.; Raj, W.; Kozanecki, M.; Matyjaszewski, K.; Pietrasik, J. Synthesis and characterization of Ag NPs templated via polymerization induced self-assembly. Polymer 2017, 129, 144-150. [CrossRef]

14. Alzahrani, A.; Zhou, D.W.; Kuchel, R.P.; Zetterlund, P.B.; Aldabbagh, F. Polymerization-induced self-assembly based on ATRP in supercritical carbon dioxide. Polym. Chem. 2019, 10, 2658-2665. [CrossRef]

15. Qiao, X.D.; Lansalot, M.; Bourgeat-Lami, E.; Charleux, B. Nitroxide-Mediated Polymerization-Induced Self-Assembly of Poly(poly(ethylene oxide) methyl ether methacrylate-co-styrene)-b-poly(n-butyl methacrylate-co-styrene) Amphiphilic Block Copolymers. Macromolecules 2013, 46, 4285-4295. [CrossRef]

16. Tan, J.; Dai, X.; Zhang, Y.; Yu, L.; Sun, H.; Zhang, L. Photoinitiated Polymerization-Induced Self-Assembly via Visible Light-Induced RAFT-Mediated Emulsion Polymerization. ACS Macro Lett. 2019, 8, $205-212$. [CrossRef]

17. Ni, Y.Y.; Tian, C.; Zhang, L.F.; Cheng, Z.P.; Zhu, X.L. Photocontrolled Iodine-Mediated Green Reversible-Deactivation Radical Polymerization of Methacrylates: Effect of Water in the Polymerization System. ACS Macro Lett. 2019, 8, 1419-1425. [CrossRef]

18. Yeow, J.; Boyer, C. Photoinitiated Polymerization-Induced Self-Assembly (Photo-PISA): New Insights and Opportunities. Adv. Sci. 2017, 4, 1700137. [CrossRef]

19. Docherty, P.J.; Derry, M.J.; Armes, S.P. RAFT dispersion polymerization of glycidyl methacrylate for the synthesis of epoxy-functional block copolymer nanoparticles in mineral oil. Polym. Chem. 2019, 10, 603-611. [CrossRef]

20. Hatton, F.L.; Lovett, J.R.; Armes, S.P. Synthesis of well-defined epoxy-functional spherical nanoparticles by RAFT aqueous emulsion polymerization. Polym. Chem. 2017, 8, 4856-4868. [CrossRef]

21. Liu, Z.Z.; Zhang, G.J.; Lu, W.; Huang, Y.J.; Zhang, J.W.; Chen, T. UV light-initiated RAFT polymerization induced self-assembly. Polym. Chem. 2015, 6, 6129-6132. [CrossRef]

22. David, G.; Boyer, C.; Tonnar, J.; Ameduri, B.; Lacroix-Desmazes, P.; Boutevin, B. Use of iodocompounds in radical polymerization. Chem. Rev. 2006, 106, 3936-3962. [CrossRef] [PubMed]

23. Bai, L.J.; Zhang, L.F.; Liu, Y.; Pan, X.Q.; Cheng, Z.P.; Zhu, X.L. Triphenylphosphine as phosphorus catalyst for reversible chain-transfer catalyzed polymerization (RTCP). Polym. Chem. 2013, 4, 3069-3076. [CrossRef]

24. Tonnar, J.; Lacroix-Desmazes, P. Controlled radical polymerization of styrene by iodine transfer polymerization (ITP) in ab initio emulsion polymerization. Polymer 2016, 106, 267-274. [CrossRef]

25. Ni, Y.Y.; Zhang, L.F.; Cheng, Z.P.; Zhu, X.L. 1 Iodine-mediated reversible-deactivation radical polymerization: A powerful strategy for polymer synthesis. Polym. Chem. 2019, 10, 2504-2515. [CrossRef]

26. Xiao, Q.L.; Sakakibara, K.; Tsujii, Y.; Goto, A. Organocatalyzed Living Radical Polymerization via in Situ Halogen Exchange of Alkyl Bromides to Alkyl Iodides. Macromolecules 2017, 50, 1882-1891. [CrossRef]

27. Liu, X.D.; Xu, Q.H.; Zhang, L.F.; Cheng, Z.P.; Zhu, X.L. Visible-light-induced living radical polymerization using in situ bromine-iodine transformation as an internal boost. Polym. Chem. 2017, 8, 2538-2551. [CrossRef]

28. Blackman, L.D.; Varlas, S.; Arno, M.C.; Fayter, A.; Gibson, M.I.; O’Reilly, R.K. Permeable Protein-Loaded Polymersome Cascade Nanoreactors by Polymerization-Induced Self-Assembly. ACS Macro Lett. 2017, 6, 1263-1267. [CrossRef]

29. Xu, Q.H.; Tian, C.; Zhang, L.F.; Cheng, Z.P.; Zhu, X.L. Photo-Controlled Polymerization-Induced Self-Assembly (Photo-PISA): A Novel Strategy Using In Situ Bromine-Iodine Transformation Living Radical Polymerization. Macromol. Rapid Commun. 2019, 40, 18004327. [CrossRef]

30. Wang, Z.H.; Pan, X.C.; Fu, L.Y.; Lathwal, S.; Olszewski, M.; Yan, J.J.; Enciso, A.E.; Wang, Z.T.; Xia, H.S.; Matyjaszewski, K. Ultrasonication-Induced Aqueous Atom Transfer Radical Polymerization. ACS Macro Lett. 2018, 7, 275-280. [CrossRef]

31. Goto, A.; Suzuki, T.; Ohfuji, H.; Tanishima, M.; Fukuda, T.; Tsujii, Y.; Kaji, H. Reversible Complexation Mediated Living Radical Polymerization (RCMP) Using Organic Catalysts. Macromolecules 2011, 44, 8709-8715. [CrossRef]

32. Goto, A.; Ohtsuki, A.; Ohfuji, H.; Tanishima, M.; Kaji, H. Reversible Generation of a Carbon-Centered Radical from Alkyl Iodide Using Organic Salts and Their Application as Organic Catalysts in Living Radical Polymerization. J. Am. Chem. Soc. 2013, 135, 11131-11139. [CrossRef] [PubMed] 
33. Liu, X.D.; Zhang, L.F.; Cheng, Z.P.; Zhu, X.L. Catalyst-free iodine-mediated living radical polymerization under irradiation over a wide visible-light spectral scope. Polym. Chem. 2016, 7, 3576-3588. [CrossRef]

34. Liu, X.D.; Zhang, L.F.; Cheng, Z.P.; Zhu, X.L. Straightforward catalyst/solvent-free iodine-mediated living radical polymerization of functional monomers driven by visible light irradiation. Chem. Commun. 2016, 52, 10850-10853. [CrossRef]

35. Cavallo, G.; Metrangolo, P.; Milani, R.; Pilati, T.; Priimagi, A.; Resnati, G.; Terraneo, G. The Halogen Bond. Chem. Rev. 2016, 116, 2478-2601. [CrossRef]

(C) 2020 by the authors. Licensee MDPI, Basel, Switzerland. This article is an open access article distributed under the terms and conditions of the Creative Commons Attribution (CC BY) license (http://creativecommons.org/licenses/by/4.0/). 